\title{
Cotton and Surgical Masks-What Ecological Factors Are Relevant for Their Sustainability?
}

\author{
Mélanie Schmutz ${ }^{1}$, Roland Hischier ${ }^{1}{ }^{10}$, Till Batt ${ }^{2}$, Peter Wick ${ }^{3}$, Bernd Nowack ${ }^{1}{ }^{(\mathbb{D}}$, \\ Patrick Wäger ${ }^{1}$ and Claudia Som ${ }^{1, *}$ \\ 1 Technology and Society Laboratory, Swiss Federal Laboratories for Materials Science and \\ Technology (Empa), CH-9014 St. Gallen, Switzerland; melanie.schmutz@empa.ch (M.S.); \\ roland.hischier@empa.ch (R.H.); bernd.nowack@empa.ch (B.N.); patrick.waeger@empa.ch (P.W.) \\ 2 Biomimetic Membranes and Textiles Laboratory, Swiss Federal Laboratories for Materials Science and \\ Technology (Empa), CH-9014 St. Gallen, Switzerland; till.batt@empa.ch \\ 3 Particles-Biology Interactions Laboratory, Swiss Federal Laboratories for Materials Science and \\ Technology (Empa), CH-9014 St. Gallen, Switzerland; peter.wick@empa.ch \\ * Correspondence: claudia.som@empa.ch
}

Received: 15 October 2020; Accepted: 4 December 2020; Published: 8 December 2020

\begin{abstract}
With the COVID-19 pandemic, wearing facemasks became common. Many initiatives arose to develop new types of reusable textile masks in order to overcome a shortage of surgical masks for the health care personnel and for the civil society. Having such high demand of facemasks raises the question about what factors define their environmental sustainability. This paper presents a first simplified Life-Cycle-Assessment (LCA) comparing surgical masks and 2-layered cotton masks. The aim of the paper is to identify and understand the relevant ecological factors in order to support decision making on how textile masks could be designed in a more sustainable manner. The results of our simplified LCA show that the cotton masks were performing better than the surgical masks and vice versa depending on the environmental impact that was looked at. It was also found that the lifespan and the weight of the cotton masks are two variables having a great importance for their overall environmental performance.
\end{abstract}

Keywords: facemask; environmental sustainability; life-cycle-assessment; decision support; sustainable design

\section{Introduction}

The COVID-19 disease originated by a SARS-CoV-2 infection and caused a global crisis. Only non-pharmaceutical measures like physical distancing, hand hygiene, or proximity tracing and testing are currently available to reduce the transmission of the virus and avoid more strict measures like national lock downs. In addition, facemasks are a meaningful measure if distancing is not guaranteed [1] like in health care settings, shops, or public transportation. This leads to a worldwide demand of surgical- and filtering face piece (FFP according EN 149:2009) protection masks. The consumption of masks will very probably further increase based on the development of the SARS-CoV-2 crisis and an expectance of future pandemics caused by other virus events during the next years. It was estimated by The World Health Organization (WHO) that 89 million medical masks for health workers are required for the COVID-19 response each month [2]. To meet with this increased demand, WHO called for an increased manufacturing by $40 \%$ [2]. In Switzerland, the National COVID-19 Science Task Force estimated in April 2020 [3] that around 4 million masks are required by the community per day in the country with the present crisis of COVID-19. The COVID-19 crisis has also provoked the development of new types of mask especially in the context of (a) the shortage 
of masks for the health care personnel and for the civil society, (b) the dependency from imports, and (c) the transfer of the virus from presymptomatic individuals. Currently on the market, there are three types of one-way surgical masks described in EN 14683:2019 (type I, II, and IIR) [4,5] and different types of washable textile masks, such as cotton, also called community masks, which are not regulated yet. For the latter, various initiatives worldwide were initiated to develop and produce textile masks aside the established surgical- or FFP protection masks that could contribute to reduce transfection rate as a source control measure (e.g., https://www.remask.ch/). However, many of these textile masks are still under development in order to achieve efficacy requirements regarding breathability, droplet resistance, filtration efficiency, reusability and fit. The Swiss National COVID-19 Science Task Force [6] as well as the French Standardization Association (AFNOR) have published recommendations on minimal specification for community masks [7]. One significant benefit of textile-based masks is the reusability compared to the disposable surgical mask.

With the increasing global demand of facemasks, the question about their environmental sustainability raises. The topic of masks is very complex as there are many different design approaches (fiber materials, number of layers, finishing) in development for community masks. To our knowledge, only one study investigated the environmental impacts of facemasks, comparing N95 masks with reusable cotton masks [8]. However, comparing those two masks seems to be inappropriate as the efficacy of both masks is not on the same level (N95 being much higher than the cotton mask), and thus comparing cotton masks with surgical masks seems to make more sense. In addition, no hotspots were identified to improve the sustainability of textile masks. With this paper we intend to identify, understand, and get a first idea of the most relevant ecological factors in order to provide a starting point on how textile community masks could be designed in an ecological sustainable manner. For this, we conducted a simplified Life Cycle Assessment (LCA) comparing surgical masks and 2-layered cotton masks in order to get a first base for decision-making for innovative industries in a quick changing market.

\section{Materials and Methods}

A simplified LCA study was conducted in order to assess the environmental impacts of surgical and cotton masks. The issue of the efficacy of masks is explicitly not a part of these investigations. The present study is considered a simplified LCA as the calculations were made directly in Microsoft Excel using the Life Cycle Impact Assessment (LCIA) results from the different materials and/or services of the ecoinvent database version 3.7, recycled-content model [9]. In order to get a first overview, the following three midpoint impact categories were considered: (1) Global Warming Potential (hereafter Carbon Footprint) in $\mathrm{kg} \mathrm{CO}_{2}$-equivalents (CO2-eq) according to the IPCC method [10], (2) Non-renewable Cumulative Energy Demand (nr-CED) in MJ-eq according to VDI definition [11], (3) Water Depletion in $\mathrm{m}^{3}$ water-eq (hereafter Water Footprint) according to the AWARE methodology [12]. In addition to these three midpoint categories, the overall environmental impacts, expressed in ecopoints according to the Swiss method of the Ecological Scarcity [13] were taken into account as well. The results of the ecological scarcity method have been calculated with version 3.6 of ecoinvent, representing the latest accurate version of this method when writing this manuscript.

To compare both types of masks, we used as functional unit one person in Switzerland wearing facemasks during one working week when traveling to work with public transports and going three times in a shop. Two different user behavior scenarios (a strict and a less strict scenario, see Table 1) were modelled in order to show the influence of human behaviors. In the stricter scenario, the person owns (as a minimum) 2 cotton masks to wear a clean mask every day. Over one week, this results, on the one hand, in washing the two masks 6 times assuming that each time this takes place in half-full washing machine at $60{ }^{\circ} \mathrm{C}$ as recommended by the Swiss National COVID-19 Science Task Force [6]. On the other hand, 13 surgical masks can be worn (1 mask per way to work travel and 1 mask whenever he/she goes in a shop). The less strict scenario represents a potential behavior people may have, even though not recommended from a health perspective. In this scenario the person either wears one 
cotton mask during the week (the same one) and washes it at the end of the week in a half-full washing machine at $40{ }^{\circ} \mathrm{C}$ or wears 6 surgical masks (one per day).

Table 1. Scenarios for one working week.

\begin{tabular}{|c|c|c|c|c|}
\hline \multirow{2}{*}{$\begin{array}{l}\text { Covered } \\
\text { Aspects }\end{array}$} & \multicolumn{2}{|c|}{ Stricter Scenario } & \multicolumn{2}{|c|}{ Less Strict Scenario } \\
\hline & Cotton Mask & Surgical Mask & Cotton Mask & Surgical Mask \\
\hline Wearing & $\begin{array}{c}2 \text { masks for a } \\
\text { working week } \\
\text { (each one used one } \\
\text { day, then washed) }\end{array}$ & $\begin{array}{l}13 \text { masks }(5 \times 2 \\
\text { travels to work }+3 \\
\text { times shopping) }\end{array}$ & $\begin{array}{l}1 \text { mask for the } \\
\text { entire week }\end{array}$ & $\begin{array}{c}6 \text { masks per week } \\
\text { (1 per open day, } \\
\text { assuming Sunday } \\
\text { is closed) }\end{array}$ \\
\hline Washing & $\begin{array}{l}\text { At the end of the } \\
\text { day (at } 60^{\circ} \mathrm{C} \text { in } \\
\text { half-full machine); } \\
\text { total of } 6 \text { washing }\end{array}$ & - & $\begin{array}{l}\text { Once a week at } 40 \\
{ }^{\circ} \mathrm{C} \text { with a half-full } \\
\text { washing machine }\end{array}$ & - \\
\hline Lifespan & $\begin{array}{l}5 \text { washing cycles } \\
\text { per mask ( } 6 \text { times } \\
\text { use) }\end{array}$ & One-way masks & $\begin{array}{l}15 \text { washing cycles } \\
\text { (16 times use) }\end{array}$ & One-way masks \\
\hline End-of-Life & Incineration & Incineration & Incineration & Incineration \\
\hline
\end{tabular}

The washing machine was assumed to be half-full, which is a typical situation in Europe [14]. For one washing-cycle $84 \mathrm{~g}$ of a representative European powder detergent have been used as reported in Golsteijn et al. (2015) [15]. For simplicity, both masks in both scenarios are incinerated at their End-of-Life (EoL). As generally stated, surgical masks are one-way masks as they are used once and then incinerated. Cotton masks, on the other hand, may have different lifespans, which is measured here as the number of times cotton masks are washed before they are incinerated. For the stricter scenario, the lifespan was set at 5 washing cycles (i.e., the 2 masks can be worn for a total of 2 weeks). The reason behind is that according to the current recommendation of the Swiss National COVID-19 Task Force for the community masks the cotton masks should be washable at least 5 times and should be washed at $60^{\circ} \mathrm{C}[6]$. For the less strict scenario, we assumed that the cotton mask is washed 15 times at $40^{\circ} \mathrm{C}$ before being thrown away, as we believe it to be another potential behavior. The system boundaries are shown in Figure 1, including all steps from the production of the different parts of the respective mask to the final disposal in an incineration plant. As most masks are globally produced, we used the respective global market data from ecoinvent; datasets that already include average transport efforts between the different process steps. The material flows for each type of mask are listed in Table 2 and an overview of the exact datasets used for the calculations can be found in the SI. The weight of the cotton mask and the surgical mask were measured in house. The total weight of the cotton mask was $11.75 \mathrm{~g}$ (two layers mask) and that of the surgical masks was $2.88 \mathrm{~g}$. Surgical masks are usually made of three layers of polypropylene nonwovens. The inner and outer fabric layer is usually spunlaid and the middle layer is meltblown [16]. It was assumed that the three layers had the same weight (total weight of the three layers equals $2.45 \mathrm{~g}$ ).

For the elastic bands, the nose wire and the meltblown layer (middle layer) no direct fitting datasets could be found in ecoinvent. Thus, for the elastic bands we used the datasets "polyurethane, flexible foam" as a proxy for the material and "extrusion, plastic pipes" for the production of the elastic bands. The nose wire was modelled with "aluminium, wrought alloy", and "section bar extrusion, aluminium", and "polypropylene, granulate" and "blow moulding" have been used for the production of the middle layer of the surgical mask. 


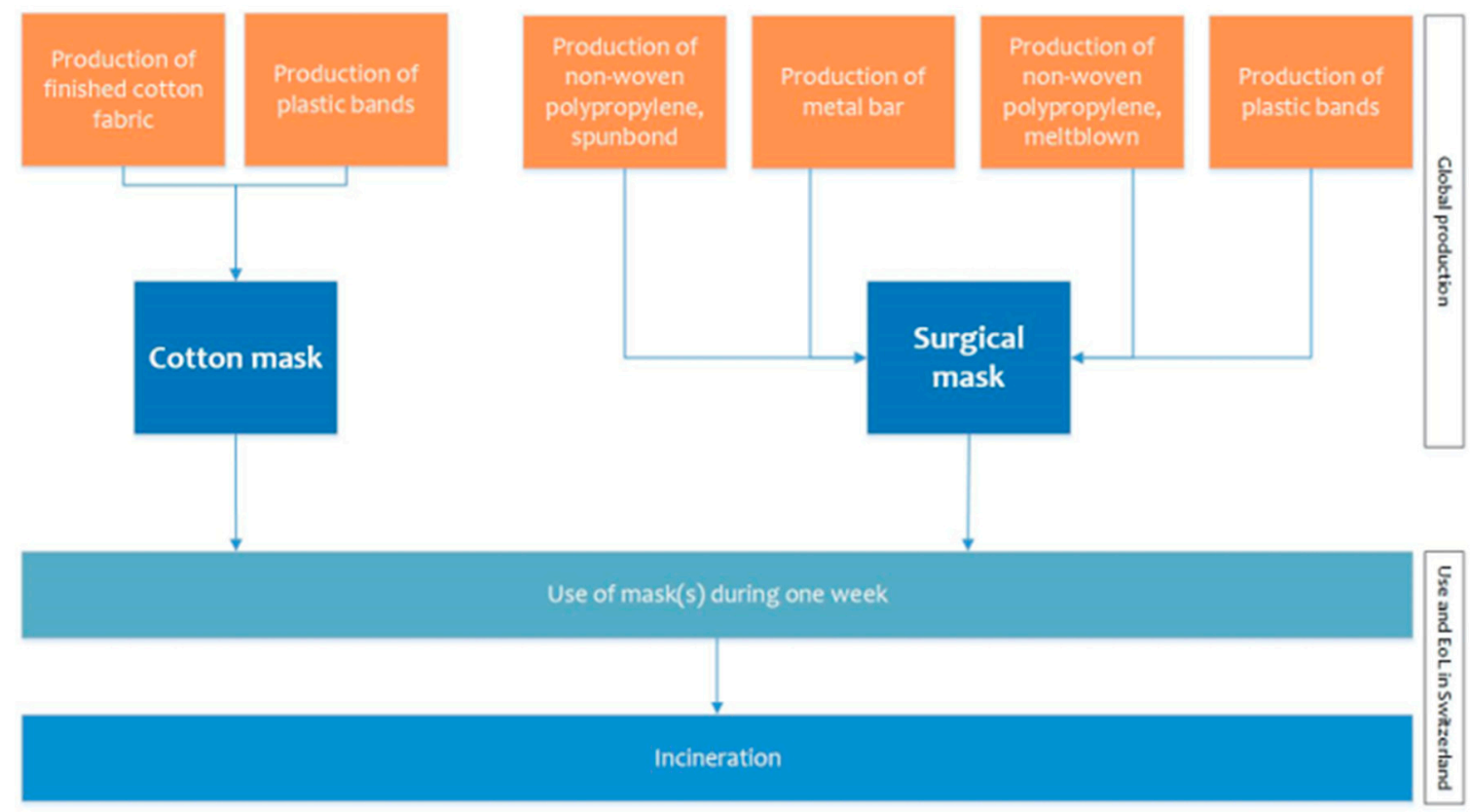

Figure 1. System boundaries of the surgical and cotton masks.

Table 2. Reference flows of the surgical and cotton masks.

\begin{tabular}{|c|c|}
\hline Surgical Mask & Cotton Mask \\
\hline $\begin{array}{ll}- & \text { Polypropylene (PP) surgical mask: } 2.45 \mathrm{~g} \text {, as } 1.63 \mathrm{~g} \text { PP spunbond } \\
\text { (inner and outer layer) } 0.82 \mathrm{~g} \text { PP meltblown (middle layer) } \\
\text { - } \quad \text { Elastic bands (polyurethane): } 0.25 \mathrm{~g} \\
\text { - } \quad \text { Nose wire (aluminium): } 0.18 \mathrm{~g}\end{array}$ & $\begin{array}{l}\text { - Cotton mask: } 11.5 \mathrm{~g} \text { cotton } \\
\text { - } \quad \text { Elastic bands (polyurethane): } 0.25 \mathrm{~g}\end{array}$ \\
\hline
\end{tabular}

\section{Results}

The surgical masks and cotton masks were compared via the two scenarios presented above, with the outcomes shown in Figures 2 and 3. Figure 2 shows the results of the four investigated impacts for the stricter scenario (as defined in Table 1). In this scenario, wearing cotton masks results in a higher environmental footprint for two of the impact categories when comparing with wearing surgical masks, i.e., the Water Footprint $\left(3.5 \mathrm{~m}^{3}\right.$ Water-eq compared to $0.07 \mathrm{~m}^{3}$ Water-eq) and for the Ecological Scarcity (924 ecopoints compared to 255 ecopoints). However, the cotton masks have a lower impact for the nr-CED than surgical masks (2.8 MJ-eq compared to $3.7 \mathrm{MJ}-\mathrm{eq}$ ). For the Carbon Footprint the impact of both type of masks are about equivalent $\left(0.23 \mathrm{~kg} \mathrm{CO}_{2}\right.$-eq compared to $0.24 \mathrm{~kg} \mathrm{CO}$-eq). For all examined impact categories, the impact of the cotton masks and the surgical masks mostly come from their respective production. The washing of the cotton masks plays only a minor role compared to the production. The impacts of the incineration of both types of masks are relatively low, except for the Carbon Footprint of the surgical masks, where the incineration contributes to $36 \%$ of the total impact. This higher relevance of the incineration process for the surgical mask comes from the fact that burning PP results in fossil $\mathrm{CO}_{2}$ emissions, while incinerating cotton results in biogenic $\mathrm{CO}_{2}$ emissions. Biogenic $\mathrm{CO}_{2}$ emissions are not taken into account in the calculation of the Global Warming Potential value for the incineration, as they represent the same amount of emitted $\mathrm{CO}_{2}$ as the plant has bound beforehand during its growth phase. 


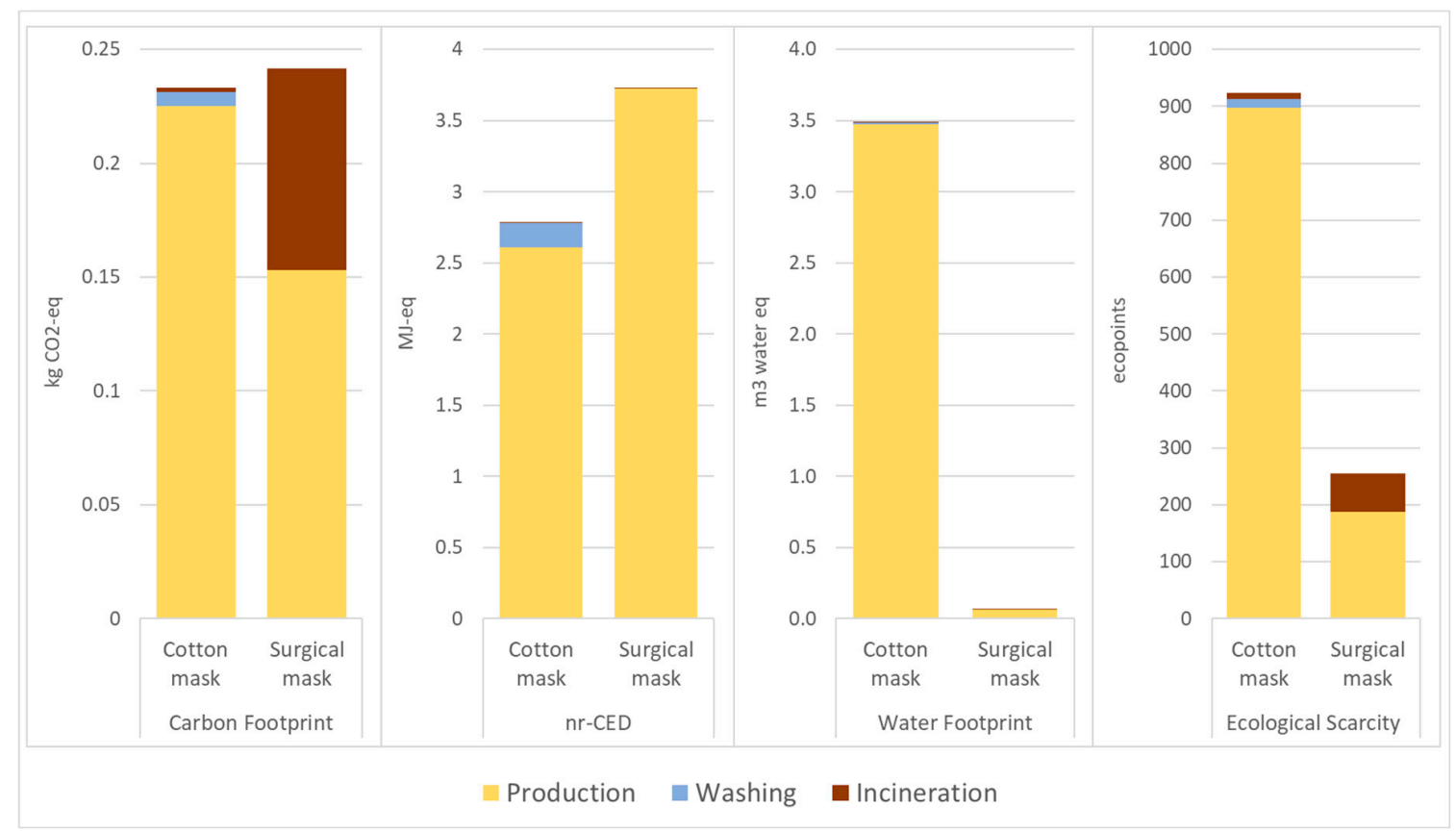

Figure 2. Comparison of stricter scenario for the cotton mask and the surgical mask. The Carbon Footprint is expressed in $\mathrm{kg} \mathrm{CO}_{2}$-eq, the Water Footprint in $\mathrm{m}^{3}$ Water-eq, the Non-renewable Cumulative Energy Demand (nr-CED) in MJ-eq, and the Ecological Scarcity in ecopoints.

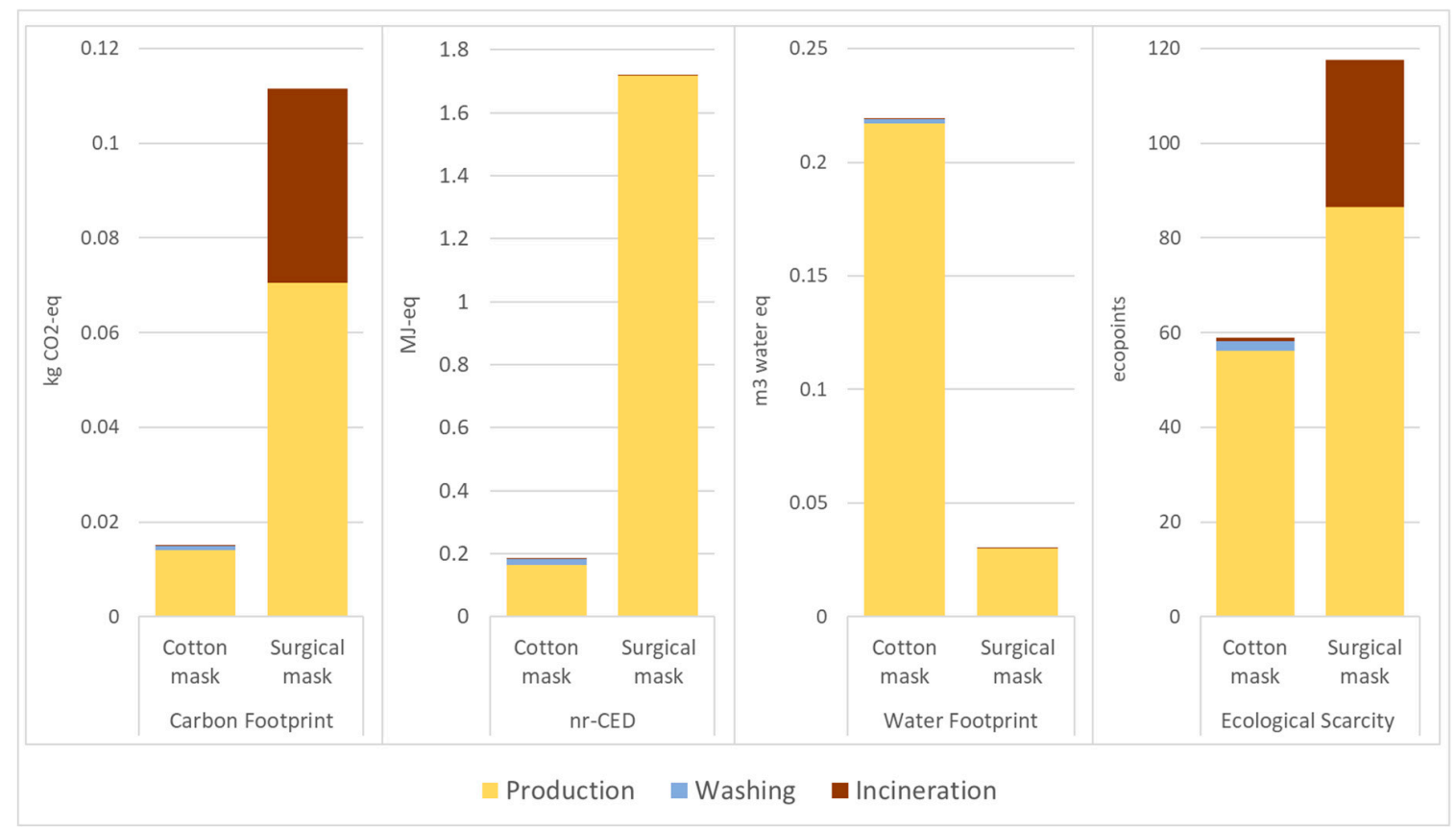

Figure 3. Comparison of less strict scenario for the cotton mask and the surgical mask. The Carbon Footprint is expressed in $\mathrm{kg} \mathrm{CO}_{2}$-eq, the Water Footprint in $\mathrm{m}^{3}$ Water-eq, the nr-CED in MJ-eq, and the Ecological Scarcity in ecopoints.

In the case of the less strict scenario (as described in Table 1), the results are quite different from those of the stricter scenario, as shown in Figure 3. Here the cotton mask results in a lower impact compared to the surgical masks for the Carbon Footprint, the nr-CED and the Ecological Scarcity. However, it still has a higher Water Footprint than the surgical masks. As for the stricter scenario, most of the impact of the two types of masks are coming from their production with the incineration of the 
surgical masks showing a relevant contribution again only for the Carbon Footprint (i.e., $36 \%$ of the total impacts).

As in both investigated scenarios the production of the two types of masks stands for the majority of the environmental impacts, further analyses were performed in order to understand which processes of the production had the most influence on those impacts. Figure 4 shows the relative importance of the different steps for the production of a cotton mask. For all four impacts, it is the fiber production that contributes most, especially for the Water Footprint and the Ecological Scarcity ( $97 \%$ and 58\%, respectively). For the Carbon Footprint and the nr-CED, three other production's step contribute as well in a relevant manner to the overall impacts, i.e., the dyeing step ( $21 \%$ and $25 \%$, respectively), the fabric production $(18 \%$ and $21 \%)$, and the yarn production $(15 \%$ and $17 \%)$. The yarn production has also a relatively high impact regarding the Ecological Scarcity (29\%). The finishing step, the assembly of the cotton mask, and the elastic band production contribute only to a minor extent to the four investigated impacts.

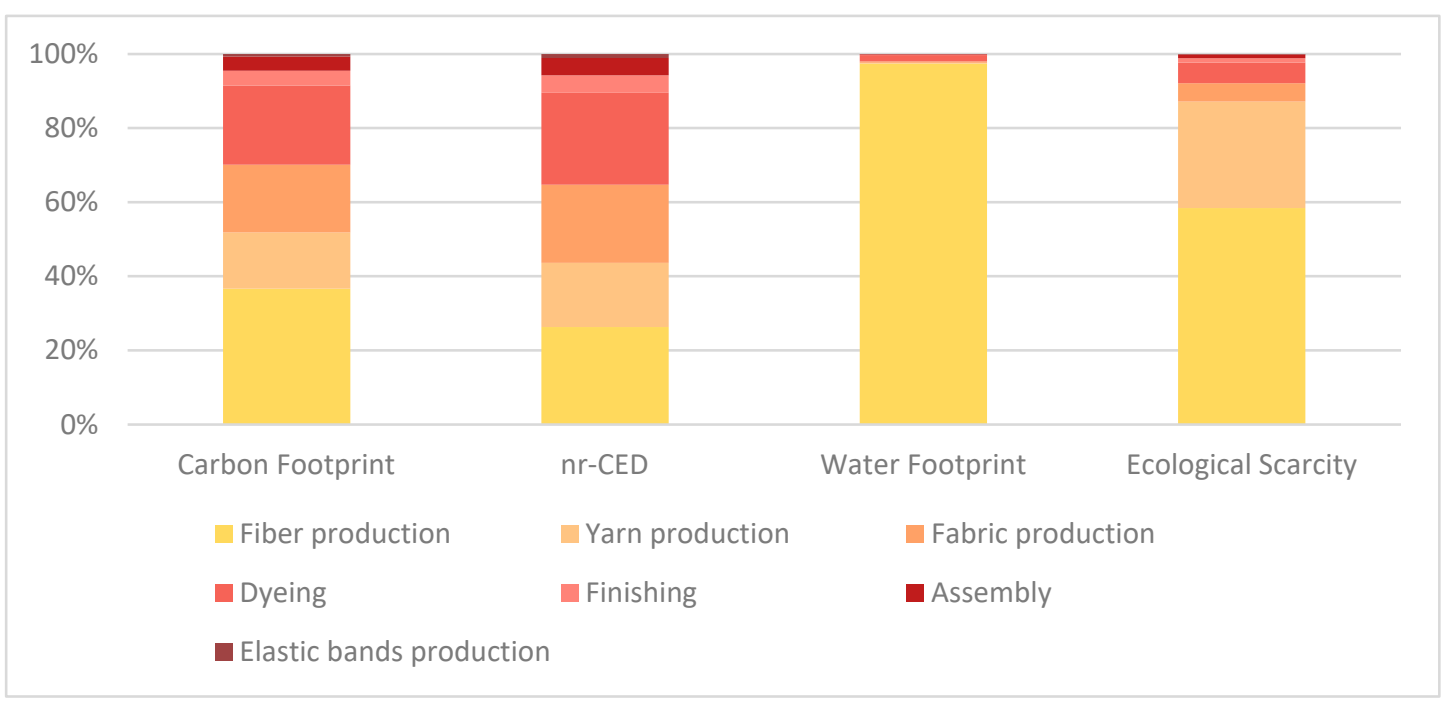

Figure 4. Relative importance of the production's steps of the cotton mask regarding the Carbon Footprint, nr-CED, Water Footprint, and Ecological Scarcity.

Figure 5 shows the relative importance of the production of the surgical mask. The non-woven PP that is spunbond contributes the most to the Carbon Footprint (40\%), nr-CED (52\%), and Water Footprint (36\%). For the Ecological Scarcity, it is the nose wire that has the most influence with 35\%. For these four impact categories, the melt-blown PP also has a relatively quite high influence (between $21 \%$ and $29 \%$ depending on the impact category). Regarding the elastic band, its relevance is the highest for the Water Footprint (28\%).

From all these investigations and analysis, two conclusions could be drawn. First, the user behavior strongly influences how the two types of masks perform environmentally (i.e., comparison of the results between the stricter and the less strict scenario). Second, the production phase contributes the most to all four here investigated impact categories. For the cotton mask, the fiber production has the highest contribution in all four cases. For the surgical mask, the various PP layers have a relatively high impact in the four investigated impact categories, while the nose wire has a relatively high influence on the result for the Ecological Scarcity. As several variables were used (see Table 1) to specify both scenarios, changing one of those could potentially influence the resulting environmental impacts of the entire system. Keeping in mind that this study aims at getting a first idea of the most relevant ecological factors for designing textile community masks in an ecological sustainable manner, extensive sensitivity analyses have been performed and are presented in the following section. 


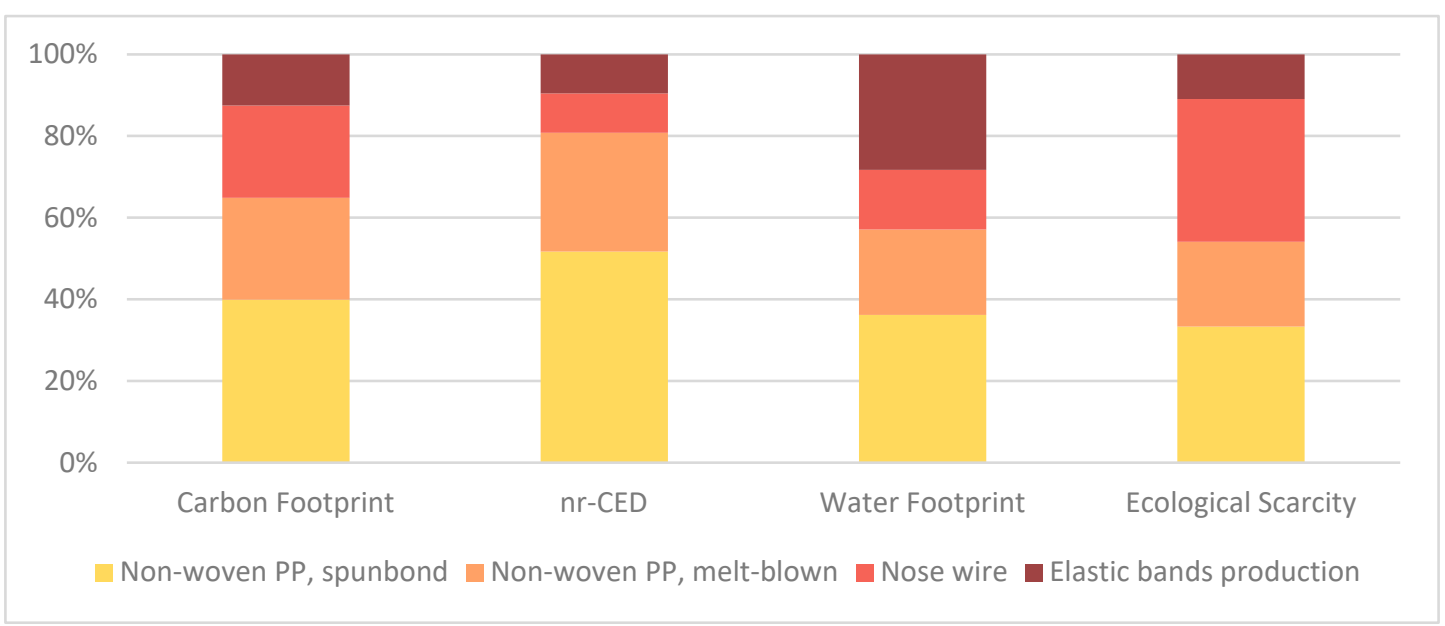

Figure 5. Relative importance of the production's steps of the surgical mask regarding the Carbon Footprint, nr-CED, Water Footprint, and Ecological Scarcity.

\section{Sensitivity Analyses}

For the sensitivity analyses, the following variables of the cotton mask were investigated for the stricter scenario: (1) the lifetime (number of washing cycles), (2) the weight of the cotton mask, (3) the washing behavior, and (4) the design of the cotton mask. The sensitivity analyses of the less strict scenario seems less relevant than the stricter scenario from the perspective of the masks' efficacy. Therefore, the sensitivity analysis of this scenario has been moved to the Supplementary Materials of this manuscript.

Table 3 shows the different scenarios investigated for the sensitivity analyses. The lifespan of cotton masks was varied between 5 washing cycles (basic scenario), 11 washing cycles (corresponds to two weeks more than the basic scenario, i.e., 4 weeks of wearing), 20 washing cycles (values that some textile companies are already achieving) and 35 washing cycles (corresponding to 12 weeks). The weight of the cotton masks was varied between $9 \mathrm{~g}$ and $20 \mathrm{~g}$, which is believed to be a reasonable range of potential weights and representing a first design possibility (either by increasing/decreasing the weight $\left(\mathrm{g} / \mathrm{m}^{2}\right)$ of the two-layer mask or by adding a third layer, thus increasing the total weight of the mask). Two other design possibilities were investigated, where a filtering layer (melt-blown PP layer) was added and where both a filtering layer, and a nose wire was added. Finally, the washing behavior was changed in several possible ways, i.e., washing at $30^{\circ} \mathrm{C}$ or $40^{\circ} \mathrm{C}$ in a half-full washing machine, or hand-washing. For the latter, two scenarios were created, one with $3 \mathrm{~L}$ of water at $55^{\circ} \mathrm{C}$ (hereafter long hand-washing) and another with $1 \mathrm{~L}$ of water at $40^{\circ} \mathrm{C}$ (hereafter short hand-washing). These two scenarios were created to cover the broad range of possible hand-washing behavior.

Table 3. Scenarios of the sensitivity analyses of the stricter scenario.

\begin{tabular}{llll}
\hline \multicolumn{1}{c}{ Lifetime } & \multicolumn{1}{c}{ Weight } & \multicolumn{1}{c}{ Washing } & \multicolumn{1}{c}{ Design } \\
\hline $\begin{array}{l}\text { 1. } 11 \text { washing cycles } \\
\text { (corresponding to } 4 \text { weeks } \\
\text { of wearing) }\end{array}$ & $\begin{array}{l}\text { 1. Low weight cotton mask } \\
\text { with } 9 \mathrm{~g} \text { cotton fabric }\end{array}$ & $\begin{array}{l}\text { 1. Washing at } 30{ }^{\circ} \mathrm{C} \\
\text { half-full washing machine }\end{array}$ & $\begin{array}{l}\text { 1. Cotton mask with a } \\
\text { filtration layer made of PP }\end{array}$ \\
$\begin{array}{l}\text { 2. } 11 \text { washing cycles } \\
\text { (corresponding to } 4 \text { weeks } \\
\text { of wearing) }\end{array}$ & $\begin{array}{l}\text { 2. High weight cotton } \\
\text { mask with } 20 \mathrm{~g} \\
\begin{array}{l}\text { 3. } 20 \text { washing cycles } \\
\text { (corresponding to } 7 \text { weeks) }\end{array}\end{array}$ & $\begin{array}{l}\text { 2. Washing at } 40{ }^{\circ} \mathrm{C} \\
\text { half-full washing machine }\end{array}$ & $\begin{array}{l}\text { 2. Cotton mask with } \\
\text { filtration layer and } \\
\text { n. } 35 \text { washing cycles } \\
\text { (corresponding } 12 \text { weeks) }\end{array}$ \\
\hline
\end{tabular}

Figure 6 shows the results of the Carbon Footprint and nr-CED. For the Carbon Footprint, the impact of the cotton masks becomes even lower when increasing the cotton masks' lifetime. 
When looking at the cotton weight, decreasing the weight of the cotton masks to $9 \mathrm{~g}$ enables the cotton masks to perform better, though to a lesser extent than when lifetime is increased. Increasing their weight to $20 \mathrm{~g}$ would, on the other hand, increases the Carbon Footprint by a factor of 1.7 ( $0.39 \mathrm{~kg} \mathrm{CO}$-eq compared to $0.23 \mathrm{~kg} \mathrm{CO}_{2}$-eq in the basic scenario) compared to the basic scenario and makes the cotton masks less performant than the surgical masks. Another point that can be seen in Figure 6 is, that the washing behavior almost does not change the overall impact when washing at $30^{\circ} \mathrm{C}$ or $40^{\circ} \mathrm{C}$ instead of washing at $60^{\circ} \mathrm{C}$, as defined for the basic scenario. However, when washing by hand, the impact increases and results in a higher impact than the surgical masks. Regarding the nr-CED, as mentioned in the results section above, the basic scenario of the cotton masks has a lower impact than the surgical masks. Not surprisingly, increasing the number of washing cycles decreases the total impact. Only two scenarios result in an increase of the impact of the cotton masks: the $20 \mathrm{~g}$ cotton masks, and the long hand-washing scenario with $3 \mathrm{~L}$ of water. The design of the cotton masks has very little influence on both the Carbon Footprint and the nr-CED.
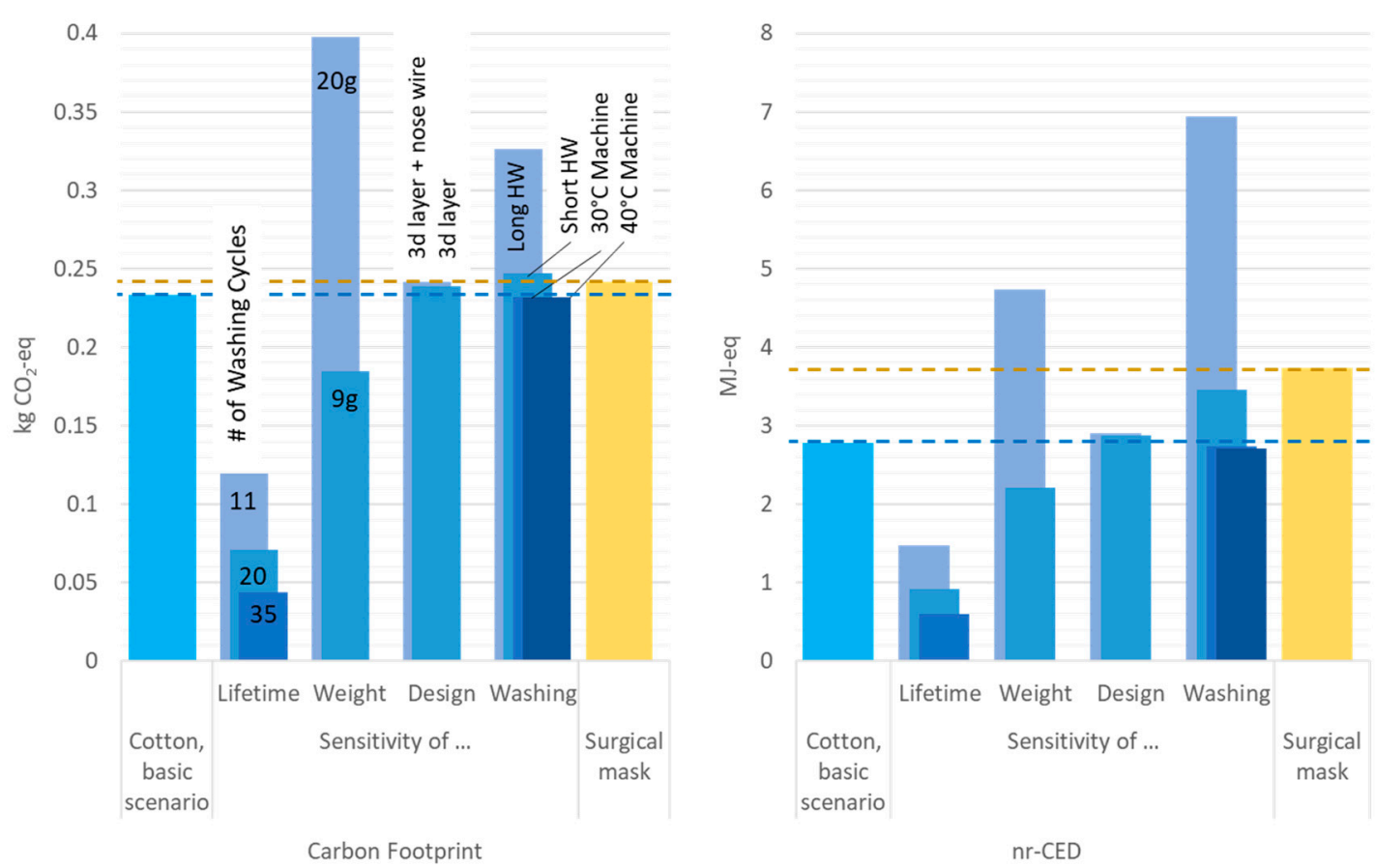

Figure 6. Sensitivity analyses of the Carbon Footprint and nr-CED for the stricter scenario. The basic scenario represents 2 masks washed at $60{ }^{\circ} \mathrm{C}$ and having a lifetime of 5 washing cycles each (total of two weeks wearing). HW: hand-washing.

As can be seen in Figure 7, in the case of the Water Footprint, the washing behavior has only a very small influence on the impacts. Increasing the lifetime of the cotton masks decreases their overall impact, which has nevertheless a higher impact than the surgical masks in the three scenarios presented here. Increasing the weight of cotton fabric to $20 \mathrm{~g}$, dramatically increases the Water Footprint by a factor of 1.7. Finally, when looking at the Ecological Scarcity, the cotton masks results in a lower impact than surgical masks only when increasing the number of washing cycles. In our scenarios, we can see that 35 washing cycles indeed lead to a lower result for the Ecological Scarcity. As for the three other investigated impact categories, the washing behavior and the design of the cotton masks does not have a big effect on the overall impact, whereas a higher weight of the cotton fabric increases it. 


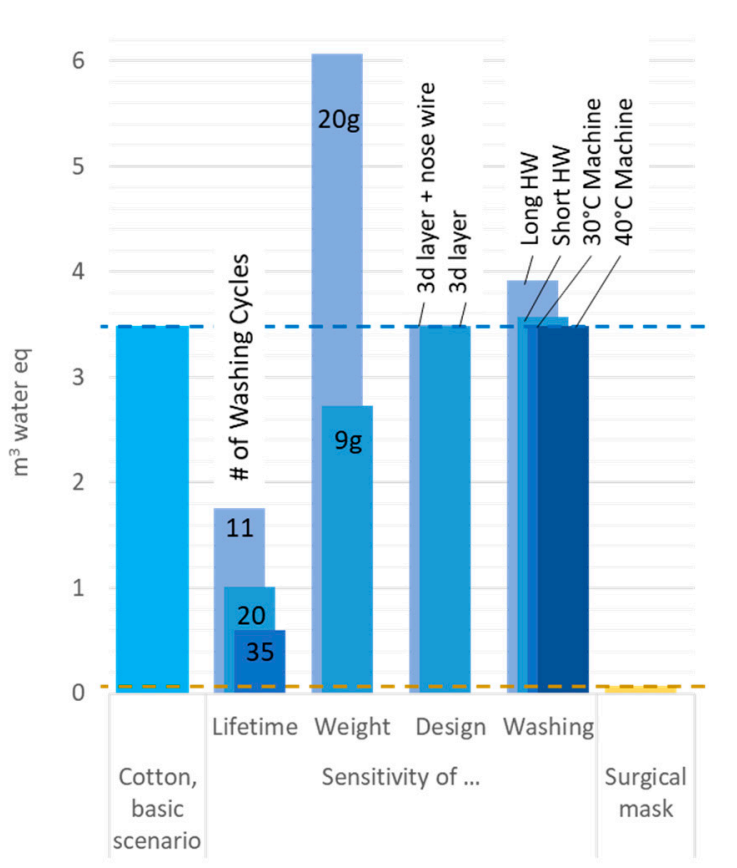

Water Footprint

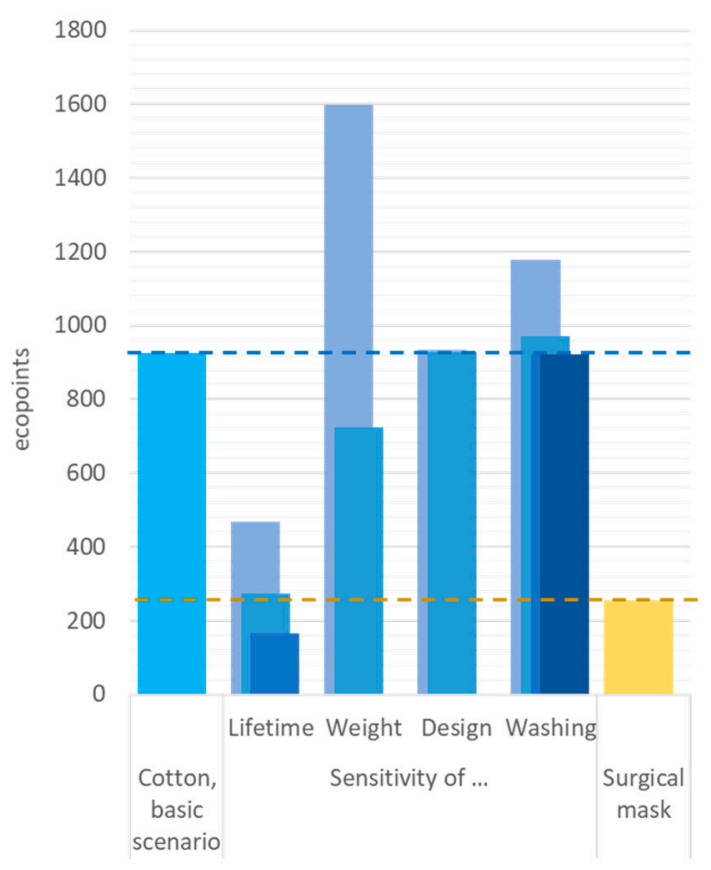

Ecological Scarcity

Figure 7. Sensitivity analyses of the Water Footprint and Ecological Scarcity for the stricter scenario. The basic scenario represents 2 masks washed at $60{ }^{\circ} \mathrm{C}$ and having a lifetime of 5 washing cycles each (total of two weeks wearing). HW: hand-washing.

For all four impact categories, increasing the lifespan of cotton masks always decreases their environmental impact, while increasing the weight of the cotton fabric to $20 \mathrm{~g}$ always results in a tremendously higher impact. The washing behavior only influences the results to a lower extent but can increase when washing by hand. In order to go a little bit deeper in the analysis, Table 4 presents the break-even points, at which the ecological advantages are switching from one type of masks to the other one.

Table 4. Ecological performance switching from one type of masks to the other one.

\begin{tabular}{ccccc}
\hline Variables & Carbon Footprint & nr-CED & Water Footprint & Ecological Scarcity \\
\hline Lifetime & $/$ & $/$ & 425 washing cycles & 22 washing cycles \\
\hline $\begin{array}{c}\text { Weight of cotton } \\
\text { mask }\end{array}$ & $12 \mathrm{~g}$ & $15.7 \mathrm{~g}$ & $/$ & $/$ \\
\hline Design & $/$ & $/$ & $/$ & $/$ \\
\hline Washing behavior & $\begin{array}{c}\text { Long and short } \\
\text { hand-washing }\end{array}$ & $\begin{array}{c}\text { Long } \\
\text { hand-washing }\end{array}$ & $/$ & $/$ \\
\hline
\end{tabular}

In yellow: the cotton masks are becoming more performant than the surgical masks. In orange: the surgical masks are becoming more performant than the cotton masks. If nothing is written, this means that whatever how the variables were changed, no switch happened, e.g., the Water Footprint of the cotton masks stays higher than the surgical masks in all the washing scenarios.

For the Water Footprint, having a lower impact than the surgical masks is only possible by increasing the number of washing cycles to 425. Similarly, for the Ecological Scarcity, an increase of the washing cycles to 22 would be required to perform better than the surgical masks. Finally, the surgical masks would perform better in terms of Carbon Footprint, if the weight of the cotton masks was increased to $12 \mathrm{~g}$ or hand-washed. This switch would also happen for the nr-CED if the weight of the cotton masks would be increased to $15.7 \mathrm{~g}$ or hand-washed with $3 \mathrm{~L}$ of water at $55^{\circ} \mathrm{C}$. 


\section{Discussion}

As presented above, the impact of the two types of masks are very much dependent on the actual use behavior. In the stricter scenario, the cotton masks have a higher environmental impact than the surgical masks in terms of Water Footprint and Ecological Scarcity, whereas in the less strict scenario only the Water Footprint of the cotton mask is higher. Although the less strict scenario has an overall lower environmental footprint, this kind of behavior is currently not recommended from a health perspective.

It should be noted that the results of the stricter scenario are not dependent on the number of masks the users have. For instance, if the user would have 6 masks instead of two, would wear 1 mask per day and wash them altogether at the end of the week, the LCA results would stay the same. The reason behind is that the number of weeks, for which the masks can be worn, increases with the number of masks the user has (two weeks for two masks instead of six weeks for six masks).

The high scores for the Water Footprint, the Ecological Scarcity and the Carbon Footprint of the cotton masks are mainly caused by the global average data for the cotton fiber production (see Figure 4), which includes intensive irrigation efforts as well as high amount of pesticides and fertilizers [17]. At the same time, as seen in the sensitivity analyses, it is possible to decrease the environmental impact of the cotton masks especially by increasing their lifespan and to a lesser extent by decreasing their weight. Washing with different temperature with the washing machine had little impact on the results, which was different for the hand-washing. The long hand-washing scenario increased the environmental impacts in all investigated impacts. Similar results were found in the work of Allison et al. (2020).

The impact of cotton masks could be further reduced, if we would use cotton that is rain-fed (therefore lowering the Water Footprint) or organically grown cotton (therefore lowering the Carbon Footprint because neither pesticides nor fossil fertilizers are used). Another potential for lowering the impacts of textile masks could be to use recycled cotton, or even use other types of materials (as according to Figure 4, the fiber production is responsible for a majority of the impacts), such as polyester; though this needs to be investigated first. The dataset for the production of cotton is a global average, as mentioned in the Materials and Methods section. This means that the variability of different production lines is not shown. Consequently, the environmental impacts of the cotton masks could greatly vary, depending on where the cotton is produced, how it is produced (e.g., irrigated or not), and where the textile fabric is manufactured and with what technology. For polypropylene fibers, we assume that variability regarding the environmental impacts among the datasets is much smaller due to highly industrialized processes for their production.

The lack of this variability within the used datasets (especially within the cotton datasets) is one of the limitations of this simplified LCA, then using (global) average data for most of the materials does simply not allow to show those variabilities within a material. Other limitations are:

- Proxies were used for the melt-blowing layer of the surgical mask, the elastic band, and the nose wire (the latter one can be made of other materials than aluminum that may have a lower environmental impact. It is also possible that the nose wire is coated with some plastics).

- Just one example of a cotton and one example of a surgical mask were modelled. No statistical investigation was made on the variety of both types of masks. For instance, other textile masks can be found in the market with other combination of fibers, such as polyester.

- The variety of cotton mask design was only to a certain extent analyzed (increase or decrease of the weight of the cotton mask representing either a change in weight of the fabric or an addition of third layer, filtering layer and nose wire). For example, chemical treatments (hydrophobicity, anti-viral, etc.), lifetime of the filtering layer, as well as different mixes of fibers were not considered so far. For surgical masks no other design was investigated. 
- Use phase and End-of-Life (100\% incinerated) modelled in Switzerland, which is not necessarily representative of other regions where the masks could have different EoL treatments, such as e.g., being landfilled.

However, with the performed sensitivity analyses, the variations examined give some security for the basic interpretation of these results and provide first indications towards improving the environmental performance of reusable masks. Some companies have already been able to increase the number of washing cycles [18]. This shows that it is feasible to achieve the break-even points for the Ecological Scarcity. One possible way to increase the lifetime of textile masks is to add an antiviral treatment, which has the potential to lower the risk of smear infections due to mask handling, thus leading to a prolonged use before washing and a longer lifetime of a mask $[19,20]$.

To conclude, this paper shows the results of a simplified LCA on facemasks. We were able to identify the most relevant factor determining the ecological sustainability of facemasks (i.e., the lifespan of the cotton masks) and to calculate the break-even points where cotton masks are performing better than surgical masks, thus providing decision support for a more sustainable design of textile community masks.

Due to the limitations of this study and the complexity of the topic (with different designs and materials of community masks), more in depth studies are needed to get a more detailed understanding of all possible masks' designs in order to maximize their ecological sustainability, while keeping their functionality. More detailed studies should look for instance at different textile masks designs, including the comparison of different materials (i.e., cotton, polyester, or mixes of these fibers), the material's origin (i.e., new material vs. recycled materials, organic cotton, etc.), its weight $\left(\mathrm{g} / \mathrm{m}^{2}\right)$, number of layers and size, and finally different possible chemical finishing. Ultimately, the design of the mask will define the washing specifications (to preserve the mask's functionality) and will need to be considered as well. The use and the end of life phase should also be evaluated for other countries having different cultures and different settings than Switzerland. Besides the environmental performance, other aspects that are not part of an LCA are relevant and need to be taken into account in such an evaluation as well. For example, concerns about other environmental aspect such as littering of surgical masks is increasing. For instance, the waste may persist in the environment and fragment into microplastics [21]. Moreover, this litter could potentially be contaminated and pose a threat to public health [21]. In this regard, the design variations of surgical masks are currently discussed in the context of bio-based and biodegradable materials are discussed [22]. All these aspects have to be taken into account in order to better understand how environmental and human health issues are interrelated in order to produce safe and sustainable textile masks. Finally, the masks should be designed for their intended purpose, meaning that they should decrease the transfection rate of diseases. In order for masks to be sustainable, they should be efficient, safe, and breathable $[6,23]$ as well as environmentally performant.

Supplementary Materials: The following are available online at http://www.mdpi.com/2071-1050/12/24/10245/s1, Tables S1-S5: used datasets for the calculations, Table S6: Scenarios of the sensitivity analysis of the less strict scenario, Figure S1: Sensitivity analysis of the Carbon Footprint and the nr-CED for the less strict scenario, Figure S2: Sensitivity analysis of the Water Footprint and the Ecological Scarcity for the less strict scenario.

Author Contributions: Conceptualization, all authors; methodology, R.H. and C.S.; formal analysis, M.S.; investigation, M.S.; data curation R.H. and C.S.; writing-original draft preparation, M.S.; writing-review and editing, all authors; visualization, R.H.; supervision, C.S.; project administration, B.N.; funding acquisition, P.W. (Patrick Wäger). All authors have read and agreed to the published version of the manuscript.

Funding: This research received no external funding.

Acknowledgments: The scenarios were developed with support of René Rossi (Head of Biomimetic Membranes and Textiles Lab) from the REMASK project (https://www.empa.ch/web/remask).

Conflicts of Interest: The authors declare no conflict of interest. 


\section{References}

1. Chu, D.K.; Akl, E.A.; Duda, S.; Solo, K.; Yaacoub, S.; Schünemann, H.J.; Urgent, C.-S. Articles Physical distancing, face masks, and eye protection to prevent person-to-person transmission of SARS-CoV-2 and COVID-19: A systematic review and meta-analysis. Lancet 2020, 395, 1973-1987. [CrossRef]

2. World Health Organization. Shortage of Personal Protective Equipment Endangering Health Workers Worldwide. Available online: https:/www.who.int/news-room/detail/03-03-2020-shortage-of-personalprotective-equipment-endangering-health-workers-worldwide (accessed on 12 October 2020).

3. Surber, M.; Rhyn, L. Hygienemasken gegen Coronaviren: Das BAG widerspricht seinen eigenen Empfehlungen. NZZ 2020. Available online: https://www.nzz.ch/schweiz/coronavirus-das-bagwiderspricht-sich-bei-schutzmasken-ld.1549423?reduced=true (accessed on 1 September 2020).

4. (EU) 2017/745 REGULATION (EU) 2017/745 OF THE EUROPEAN PARLIAMENT AND OF THE COUNCIL of 5 April 2017 on Medical Devices, Amending Directive 2001/83/EC, Regulation (EC) No 178/2002 and Regulation (EC) No 1223/2009 and Repealing Council Directives 90/385/EEC and 93/42/EE. 2017. Available online: https: //eur-lex.europa.eu/legal-content/EN/TXT/?uri=CELEX\%3A32017R0745 (accessed on 1 September 2020).

5. SR 812.213 MedDO SR 812.213 Medizinprodukteverordnung. 2001, pp. 1-46. Available online: https: //www.admin.ch/opc/de/classified-compilation/19995459/index.html (accessed on 1 September 2020).

6. NCS-TF Swiss National COVID-19 Science Task Force. Recommendations for Minimal Specifications for the Community Masks for Swiss Manufacturers (as Published on 25 April 2020). 2020, pp. 1-6. Available online: https://www.empa.ch/documents/12524755/0/22.04.2020+Community+mask+spec+ and+recommendations+for+minimal+values+V4-final.pdf/8aa76f3c-428c-46e2-b9c3-4d4af29716f2\#: $\sim\{\}:$ text=Recommended $\% 20$ specifications $\% 20$ for $\% 20$ Community $\% 20$ masks $\% 3 A \& t e x t=I n \% 20 b r i e f \%$ 3A\%20Air\%20permeability \%20\%3C\%2060,particle\%20size $\% 20$ of $\% 201 \% 20$ micrometer (accessed on 1 September 2020).

7. AFNOR. Barrier Masks—Guide to Minimum Requirements, Methods of Testing, Making and Use; AFNOR: Paris, France, 2020. Available online: https://www.afnor.org/en/news/protective-masks-download-our-referencedocument-for-free/ (accessed on 1 September 2020).

8. Allison, A.L.; Ambrose-Dempster, E.; Aparsi, T.D.; Bawn, M.; Miguel Casas Arredondo, C.C.; Chandler, K.; Dobrijevic, D.; Hailes, H.; Lettieri, P.; Liu, C.; et al. The environmental dangers of employing single-use face masks as part of a COVID-19 exit strategy. UCL Open Environ. 2020, 53, 1689-1699. [CrossRef]

9. Ecoinvent Centre. Ecoinvent Data v3.7-Recycled-Content System Model. Available online: www.ecoinvent. org (accessed on 5 September 2020).

10. Stocker, T.F.; Qin, D.; Plattner, G.-K.; Tignor, M.; Allen, S.K.; Boschung, J.; Nauels, A.; Xia, Y.; Bex, V.; Midgley, P.M. (Eds.) IPCC Climate Change 2013: The Physical Science Basis. Working Group I Contribution to the Fifth Assessment Report of the Intergovernmental Panel on Climate Change; Cambridge University Press: Cambridge, UK; New York, NY, USA, 2013.

11. Hischier, R.; Weidema, B.; Althaus, H.-J.; Bauer, C.; Doka, G.; Dones, R.; Frischknecht, R.; Hellweg, S.; Humbert, S.; Jungbluth, N. Implementation of Life Cycle Impact Assessment Methods; Ecoinvent Centre: Zürich, Switzerland, 2010.

12. European Commission. Joint Research Centre Environmental Footprint Package 3; European Commission: Brussels, Belgium, 2019.

13. Frischknecht, R.; Büsser Knöpfel, S. Ökofaktoren Schweiz 2013 Gemäss der Methode der Ökologischen knappheit. Methodische Grundlagen und Anwendung auf Die Schweiz; BAFU: Bern, Switzerland, 2013.

14. Stamminger, R.; Schmitz, A. Washing machines in Europe-Detailed assessment of consumption and performance. Tens. Surfactants Deterg. 2016, 53, 70-86. [CrossRef]

15. Golsteijn, L.; Menkveld, R.; King, H.; Schneider, C.; Schowanek, D.; Nissen, S. A compilation of life cycle studies for six household detergent product categories in Europe: The basis for product-Specific AISE Charter Advanced Sustainability Profiles. Environ. Sci. Eur. 2015, 27, 23. [CrossRef] [PubMed]

16. NCS-TF National COVID-19 Science Task Force (NCS-TF). Clarification on Face Mask Types, Architecture, Quality, Handling, Test and Certification Procedures. 2020, pp. 1-10. Available online: https:/www.snv.ch/files/content/documents/News\%20und\%20Newslettertexte/20200924_Policy\% 20Brief\%20Mask\%20Type\%20clarification\%20and\%20use.pdf (accessed on 30 August 2020). 
17. Kooistra, K.; Termorshuizen, A. The Sustainability of Cotton Consequences for Man and Environment; Science Shop Wageningen UR: Wageningen, The Netherlands, 2006.

18. TESTEX Community Mask Label. Available online: https://www.testex.com/de/communitymask/label.php (accessed on 1 December 2020).

19. Livinguard. Eine Revolutionäre Technologie, Die $>99.9 \%$ von SARS-CoV-2 Zerstört. Available online: https://livinguard.com/revolutionaere-schutzmasken/?lang=de (accessed on 13 October 2020).

20. HEIQ. HEIQ VIROBLOCK. Available online: https://heiq.com/technologies/heiq-viroblock/?no_popup=1 (accessed on 13 October 2020).

21. Prata, J.C.; Silva, A.L.P.; Walker, T.R.; Duarte, A.C.; Rocha-Santos, T. COVID-19 Pandemic Repercussions on the Use and Management of Plastics. Environ. Sci. Technol. 2020, 54, 7760-7765. [CrossRef] [PubMed]

22. Government of Canada COVID-19: Compostable Disposable Surgical Masks and Compostable Disposable Respirators Used in the Canadian Healthcare System. Available online: https:/www.ic.gc.ca/eic/site/101.nsf/ eng/00117.html (accessed on 1 December 2020).

23. Peeples, L. What the data say about wearing face masks. Nature 2020, 586, 186-189. [CrossRef] [PubMed]

Publisher's Note: MDPI stays neutral with regard to jurisdictional claims in published maps and institutional affiliations.

(C) 2020 by the authors. Licensee MDPI, Basel, Switzerland. This article is an open access article distributed under the terms and conditions of the Creative Commons Attribution (CC BY) license (http://creativecommons.org/licenses/by/4.0/). 